\title{
EDITORIAL
}

\section{Pretense in chimpanzees}

\author{
Tetsuro Matsuzawa ${ }^{1,2,3}$
}

Published online: 2 July 2020

(c) Japan Monkey Centre and Springer Japan KK, part of Springer Nature 2020

\section{Pretend play witnessed in the wild}

Chimpanzees, especially young ones, have an extraordinary photographic memory for fleeting visual events (Inoue and Matsuzawa 2007). Humans may have lost this kind of memory, in a tradeoff that saw us acquiring the power of imagination. Imagination is what allows us to think about and contemplate things we do not experience directly (Matsuzawa 2009; Saito et al. 2014). It provides the basis for language and symbol use, and also understanding others' minds, sharing ideas, and giving a helping hand. We can imagine what it is like for families and friends who might be suffering, or celebrating, in far and remote places.

The first clear evidence of imagination in human development appears in the form of pretense or pretend play. Toddlers of around 1-2 years old begin to express their imagination, with wooden blocks becoming vehicles and cardboard boxes becoming houses or shops. Pretend play is a form of symbolic play where children typically use objects or actions to represent other objects or actions using their imagination. Pretense is believed to be an innate capacity in humans because it is universal and emerges in a sequence of stages (Eible-Eibesfeldt 1989; Fein 1981; Lillard 1993; Lillard et al. 2013; Piaget 1962). The development of pretend play is quite predictable: it begins with object substitutions and transforms into more complex role-play. Piaget (1962) considered language, deferred imitation, and pretense as evidence of representational capacity in human children. These abilities are inter-related and first appear in children

Electronic supplementary material The online version of this article (https://doi.org/10.1007/s10329-020-00836-z) contains supplementary material.

Tetsuro Matsuzawa

matsuzawa.tetsuro.8w@kyoto-u.ac.jp

Kyoto University Institute for Advanced Study, Kyoto, Japan

2 Primate Research Institute, Kyoto University, Inuyama, Japan

3 Chubu University Academy for Emerging Sciences, Kasugai, Japan around 1-2 years old. But what are the evolutionary origins of pretense?

The following sections summarize my observations of pretense in chimpanzees, humans' closest evolutionary relatives. These episodes happened in natural chimpanzee habitats in Africa. Many field studies have focused on tool use to shed light on chimpanzees' behavioral flexibility and intellectual abilities (McGrew 1992; Sanz et al. 2013; Whiten et al. 1999; Yamakoshi 2001). However, much less is known about other aspects of intellect, such as imagination and symbol use. Long-running observations of chimpanzees in the wild sometimes capture interesting episodes that are related to those capabilities. This article tries to assemble various pieces of evidence that illuminate the developmental stages of pretense in chimpanzees. By also drawing on observations from captivity, I ultimately attempt to bridge fieldwork and laboratory work to understand the evolutionary bases of imagination and symbol use, long held to be unique to humans.

My colleagues and I have been studying wild chimpanzees at Bossou-Nimba, Guinea, West Africa (Sugiyama and Koman 1979; Matsuzawa et al. 2011). I started my fieldwork in February 1986, in Bossou. Since then, I have returned to the field almost every year to observe the chimpanzees. We have paid close attention to their tool use, especially their use of stone tools to crack open nuts (Matsuzawa 1994; Inoue-Nakamura and Matsuzawa 1997; Biro et al. 2003). Field experiments on tool use are carried out in two outdoor laboratories called "Bureau" and "Salon," where we have set up video cameras to record the chimpanzees' behavior. We are currently working to consolidate our footage recorded at Bossou over three decades into a systematic video archive for future analyses (Schofield et al. 2019). Thus, the episodes we witnessed in the field are not anecdotes, but videorecorded facts with fundamental information about each event: " $4 \mathrm{~W} 1 \mathrm{H}$ " (When, Where, Who, What, and How).

I will introduce three episodes of pretend play that I witnessed in the forest: (1) wearing a grass head cushion by a 3-year-old juvenile male (Fig. 1a), (2) hyrax-toying by an 8.5-year-old female, and (3) playing with a log doll by an 
a

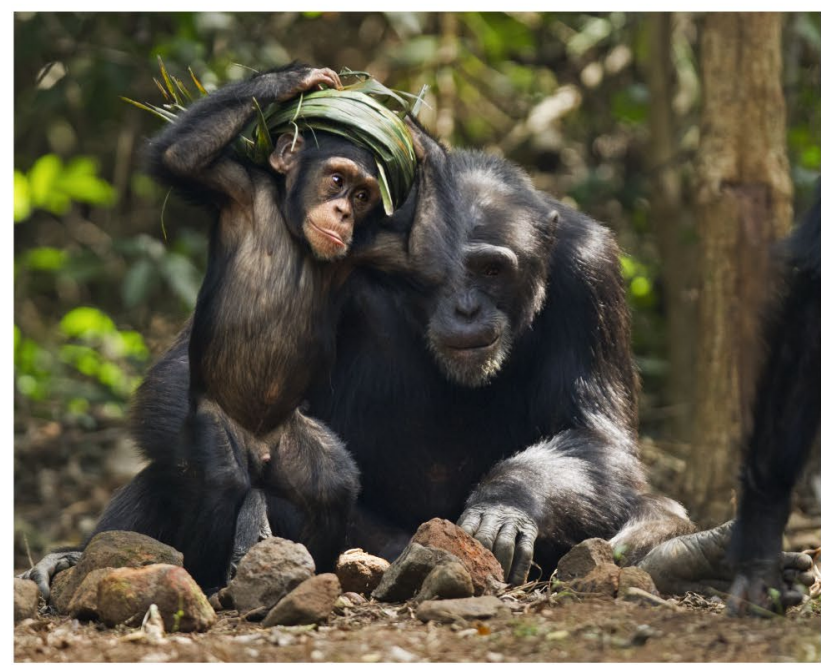

b

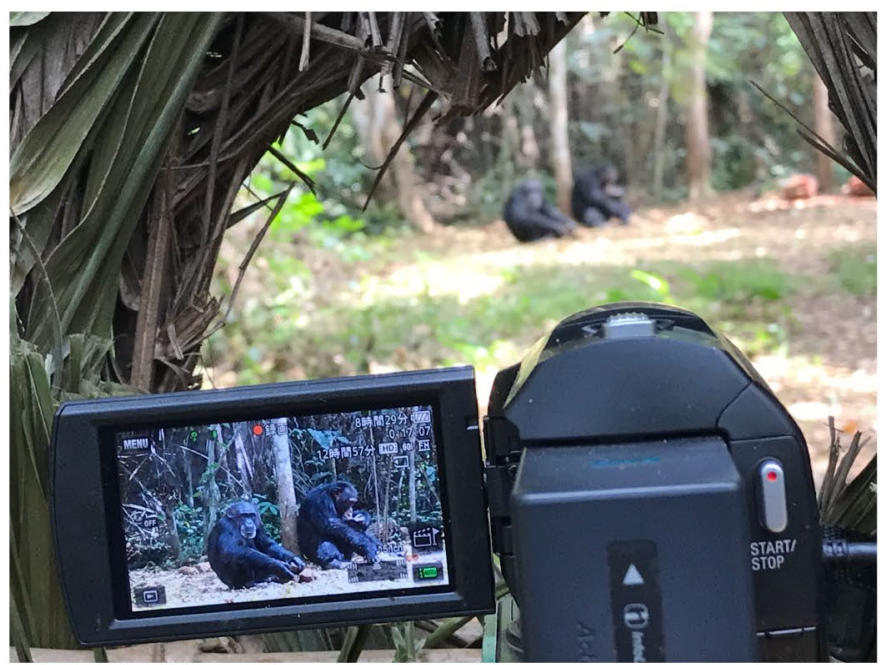

C

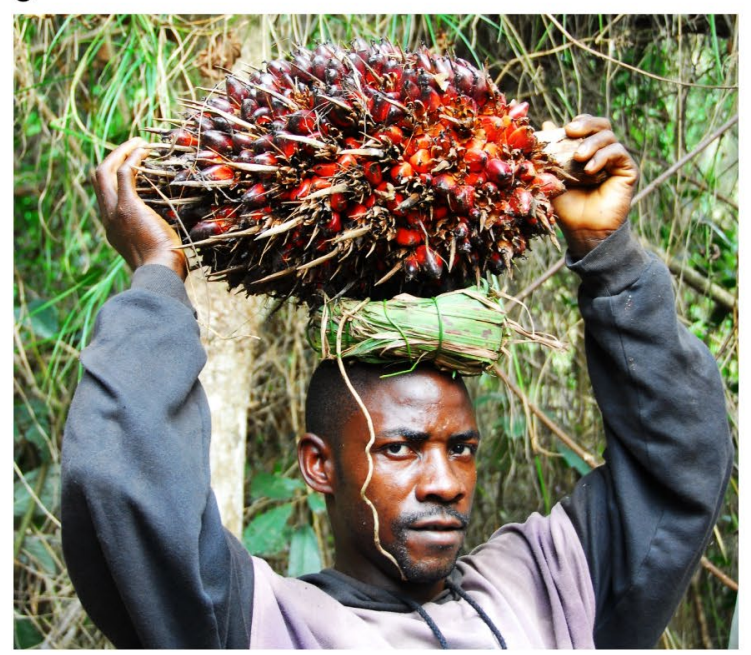

d

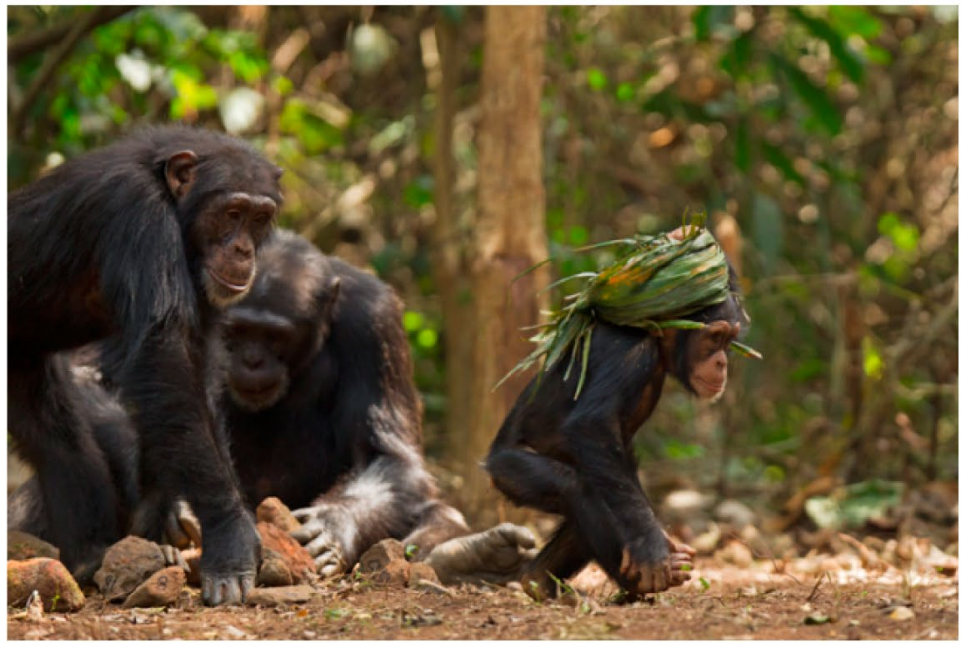

Fig. 1 a Flanle wearing grass head cushion (photo by Anup Shah and Fiona Rogers). b Outdoor laboratory named "Salon" for field experiments. We hid ourselves behind a grass fence about $15 \mathrm{~m}$ from the chimpanzees (photo by Tetsuro Matsuzawa). c Grass head cushion for transporting oil palm (photo by Shinya Yamamoto). d Flanle wearing the grass head cushion manages to evade his mother as she playfully chases him (photo by Anup Shah and Fiona Rogers)
8 -year-old female. These observations correspond to the three developmental stages of pretend play identified in children: in the first, a real object was used for play; in the second, an object that was somehow similar to the real object was used; and in the final case, an object that was quite different from the real one was used.

\section{A 3-year-old male chimpanzee wears a grass head cushion}

A young juvenile male happened to find a human-made grass head cushion used by local people for carrying loads on their heads. He immediately put it on his head while standing up and walked bipedally. The young chimpanzee, named Flanle, was born on September 14, 2007. The episode happened on January 2, 2011, when Flanle was 3 years and 3 months old. He was always accompanied by his mother, Fanle, and often by his grandmother, Fana, as well. Two researchers, Shinya Yamamoto and I, were present and video-recorded the entire episode, while two professional photographers, Anup Shah and Fiona Rogers, took pictures (two of which are used as cover illustrations for Volumes 57 and 58 of Primates). Our summary of the behavior was originally reported by Matsuzawa and Yamamoto (2011) in Japanese (Supplementary video 1 and openly accessible video: https://youtu.be/agze3WFMsuw). 
The episode happened in the "Salon" outdoor laboratory of Mont Guein, where we conducted field experiments on stone tool use for cracking oil-palm nuts. In the Salon, there were natural oil-palm trees and stones, and a tree that had a natural hollow in the trunk. Experimental manipulations were minimal: we simply added extra palm nuts to the naturally fallen ones, poured fresh water into the tree hollow, and sometimes moved the available stones around. The Salon was located on the path between two forests, so the chimpanzees frequently passed through it during their daily travels. We followed the chimpanzees every day and when it looked like they were headed towards the Salon, we went on ahead to set up our experiment and waited for them to arrive. We hid ourselves behind a grass fence about $15 \mathrm{~m}$ from the chimpanzees (Fig. 1b). During the study period from December 16, 2010 to January 5, 2011, there were in total 33 "parties" (subsets of the full group) and 163 chimpanzee visits to the Salon. The mean party size was five chimpanzees, and they stayed at the Salon for about $39 \mathrm{~min}$ on average. We recorded $1274 \mathrm{~min}$ of tool-use behavior during this period.

On January 2, we asked a local assistant to bring a "regime" of oil palm to replenish the field laboratory. One regime- the bunch in which the nuts naturally grow-contains about 300 nuts and weighs more than $10 \mathrm{~kg}$. The red, oily outer soft tissue of the nuts is eaten, and the hard shell cracked open to access the edible kernel inside as well. A regime is heavy and spiky, so to transport it villagers place a cushion on their head, and then lift the regime onto the cushion (Fig. 1c). The cushion is called "Mini" in Manon, the local language, and people using Minis in this fashion is a very common sight. Without a doubt, Bossou chimpanzees have also often seen this human way of transporting loads. Minis can be made of cloth or improvised on site using other materials such as grass and leaves. On this occasion, a porter quickly made a cushion from oil-palm leaves on which to bring the cropped regime to the Salon. When he put down the regime, the cushion also fell to the ground, where the porter abandoned it because it was of no further use to him. This was unremarkable, and the Mini merged so well into the surrounding vegetation that at first we did not notice it on the ground.

A group of six chimpanzees arrived at the Salon at 12:14: two adult males (Tua and Foaf), and two adult females (Pama and Jire) accompanied by their respective offspring (Peley, male, 12 years 8 months; Joya, female, 6 years 4 months). They started to perform two kinds of tool use behavior: using stones as anvil and hammer to crack oil-palm nuts and using leaves as sponges to drink water from the tree hollow. At 12:23, Jeje, the 13-year-old alpha male of the community, arrived and joined the tooluse session. All seven chimpanzees also started grooming each other.
At 12:33, three more chimpanzees, Fana, Fanle, and Flanle arrived. Flanle immediately found the Mini that had been left on the ground. At 12:37, he picked it up and put it on his head just like a laurel wreath or grass hat. He stood upright and walked bipedally while wearing the grass cushion, similar to what a villager might do before lifting a load onto the head (Supplementary video 1; It is also available at the following website: https://youtu.be/agze3WFMsuw). None of the other chimpanzees paid any attention except Flanle's mother, Fanle. As if she thought it might be dangerous, Fanle chased Flanle to get him to stop playing with the Mini (Fig. 1d). Bossou chimpanzees are accustomed to encountering human-made dangerous objects in the forest and are even known to break wire snares when encountered (Ohashi and Matsuzawa 2011). Flanle managed to evade his mother and continued his pretend play. Both chimpanzees then showed relaxed facial expressions, indicating that the situation was not dangerous.

The grass head cushion started to come apart because of Flanle's playful handling, and eventually turned back into a simple oil-palm leaf. At 12:41, Flanle stopped the play and turned his attention to other things and to his fellow chimpanzees. He started trying to crack open oil palm nuts with a hammer stone he held in his left hand, but he was not yet able to succeed at this. He also climbed onto his grandmother's back.

Was Flanle copying the actions of humans he had previously observed using Minis? At this point, it may be worth exploring the concept of behavioral copying in some depth. Imitation can be divided into two categories. The first is called immediate imitation, which means copying a model's action immediately in front of the model. Chimpanzees in the wild show plenty of examples of immediate imitation in the course of acquiring stone tool use. In this case, I use the word "imitation" to refer to copying behavior based on repeated exposure. Immediate imitation attempts in wild chimpanzees are not always successful. Apes do not ape. It takes a long time for young ones to learn how to use stones efficiently to crack open nuts (Inoue-Nakamura and Matsuzawa 1997). In contrast, "true imitation" means copying a completely new behavior that was not in the actor's existing repertoire. True imitation is an extreme case of immediate imitation in which behavioral copying is based on a single exposure rather than repeated ones. Laboratory tests such as the "Do this!" game have revealed that chimpanzees are capable of this kind of true imitation to some extent (Myowa-Yamakoshi and Matsuzawa 1999; 2000).

The second (and more advanced) category of imitation is called deferred imitation, in which the model's action is imitated not immediately, but some hours or days later, even in the absence of the model (Heimann and Meltzoff 1996). Deferred imitation is close to pretense in which an original thing or action is replaced with something similar. 
If we apply this definition, chimpanzee Flanle performed deferred imitation of a human model using the cushion to carry a heavy object on the head; no model was present. However, there might be another way to explain Flanle's actions: affordance (Lockman 2000). The shape of the Mini itself may afford the action of wearing it on the head. However, it is notable that the chimpanzee performed the action of not only wearing the Mini, but also adopting a human-like upright posture and walking bipedally. These facts support the interpretation that Flanle truly imitated the novel action of wearing the head cushion at the first opportune moment after repeated exposure to scenes of humans wearing Minis. This inter-species imitation involves representations of both body image and action: wearing a grass cushion and pretending to walk like humans. Therefore, I propose this episode as an example of deferred imitation and also a rudimentary form of pretend play. This observation represents the use of a real object for play as described in the introduction as one of the developmental stages of pretend play.

\section{An 8.5-year-old female chimpanzee toys with a hyrax}

In another episode, we observed that an adolescent female carried a dead hyrax into her night nest, slept with it for one night, and groomed the corpse before abandoning it later the next morning. The subject, named Vuavua, was born in the middle of 1991. The episode happened on January 18, 2000, when Vuavua was 8.5 years old. By that time, Vuavua was quite independent from her mother Velu, and was often in the company of playmates of a similar age. Four researchers, Satoshi Hirata, Shiho Fujita, Gaku Ohashi, and I, observed this episode together, and it was video-recorded by Hirata. Detailed behavioral descriptions are available in separate reports (Hirata et al. 2001; Hirata and Mizuno 2011 and documented below (Supplementary video 2 and openly accessible video: https://youtu.be/Umr3iy-OQCQ).

On January 18, we were observing a group of chimpanzees in the northern area of Mont Gban, a sacred hill covered with large trees. At 17:04, an 8-year-old male named Yolo emerged, climbed a tree, and then descended again into the bush below. At this point, a total of 13 individuals were present: two adult males (Tua and Foaf), five adult females (Fana, Jire, Kai, Velu, and Yo), one adolescent male (Yolo), two adolescent females (Vuavua and Fotaiu), one juvenile female (Juru), and two infants (Fanle and Jeje). Yolo climbed the tree holding a live western tree hyrax (Dendrohyrax dorsalis) in one hand. Juru, a 6-year-old female, followed him immediately and stayed close to him. Yolo swung the hyrax in the air, pounded it against branches several times, and wandered about in the tree with a play face. The adults did not appear interested in the hyrax, and continued to feed on fruits and leaves. Hyraxes are not in the Bossou chimpanzees' "prey image" (Boesch and Boesch 1989; Hirata et al. 2001; Hockings et al. 2012; Hosaka et al. 2020)—meaning they neither consume this species nor perceive it as potential food. At 17:09, Yolo dropped the hyrax into the low vegetation, then immediately descended, followed by Juru. The hyrax screamed intermittently.

At 17:26, Vuavua emerged from the bush, hyrax in hand, and climbed a nearby tree (Fig. 2a). The hyrax looked dead. Vuavua tapped it with her hand and foot, swung it in the air, and moved about in the tree carrying the hyrax on her shoulder or in her "thigh pocket" (i.e., holding it between her abdomen and thigh). Fotaiu (8.5-year-old female) and her young sister Fanle (2 years 3 months) approached Vuavua and stayed close to her. Three adult females passed Vuavua in succession, but none of them showed any interest in the hyrax. Vuavua carried the hyrax into another tree, and made a nest. She abandoned this first nest, carried the hyrax to another tree $30 \mathrm{~m}$ away and prepared a second nest. For about $1 \mathrm{~h}$ between 17:46 and 18:47, while in the night nest, Vuavua treated the hyrax as a chimpanzee mother might treat her infant (Fig. 2b): grooming it with her fingers and mouth.

The next morning, January 19, 2000, at 07:28, we found Vuavua with the dead hyrax in a tree near her previous night's nest: she was grooming the corpse. At 07:48, the young adult female Pili (12 years old) and her son Pokuru (3 years 4 months) approached and observed Vuavua and the hyrax. At 08:03, Vuavua descended from the tree and traveled with three other individuals, carrying the hyrax sometimes in her hand and sometimes in her thigh pocket. At 08:16, Vuavua moved away and we lost track of her until 10:36, when she no longer had the hyrax. At 14:30, we found the dead hyrax on the ground about $300 \mathrm{~m}$ away from the tree that Vuavua had first climbed with it.

The hyrax was an adult male, weighing $2.3 \mathrm{~kg}$. Its crownrump length was $42 \mathrm{~cm}$. As already mentioned, Bossou chimpanzees are not known to eat western tree hyraxes. The treatment of the hyrax by the adolescent chimpanzee can be considered as a kind of play. Similar behaviors have been witnessed in bonobos' (Pan paniscus) treatment of sympatric monkeys (Sabater Pi et al. 1993; Ihobe 1990). Sabater Pi et al. (1993), for example, observed an adult bonobo carry a dead red-tailed monkey (Cercopithecus ascanius) and groom it as if it were another bonobo.

Vuavua became pregnant the following year, and gave birth to her daughter, named Veve, in May 2001. Unfortunately, Veve died in a flu-like epidemic in 2003, at the age of 2 years 6 months (Humle 2011). Vuavua continued to carry the infant's dead body for 19 days (Biro et al. 2010, Fig. 2c). A similar kind of affection might have been underlying the maternal behavior she had shown toward the hyrax carcass. A newborn chimpanzee weighs about $1.8 \mathrm{~kg}(n=84$, Udono et al. 1999) and measures about $28 \mathrm{~cm}$ crown-to-rump 


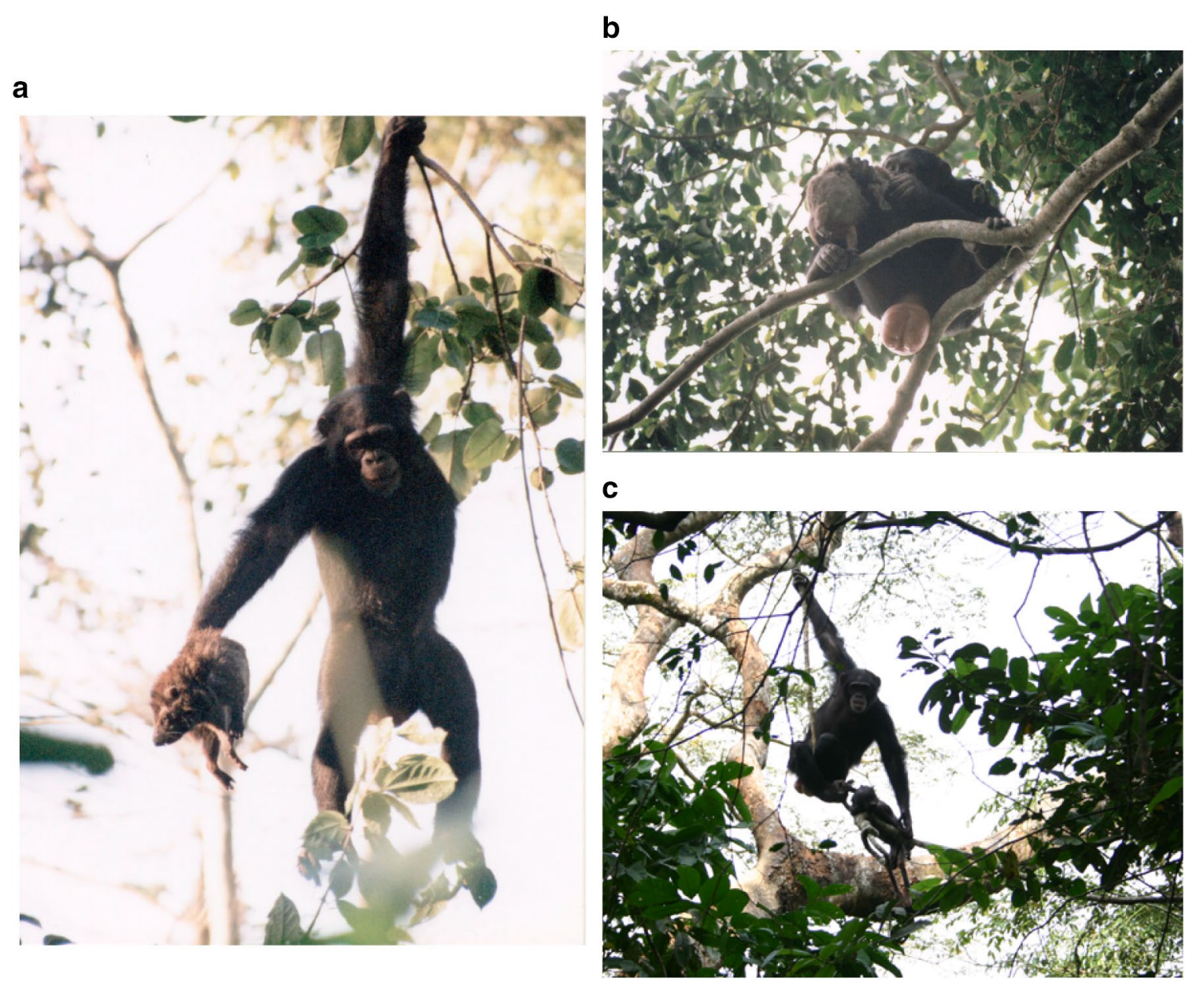

Fig. 2 a Vuavua holding the hyrax (photo by Satoshi Hirata and Gaku Ohashi). b Vuavua grooming the hyrax (photo by Satoshi Hirata and Gaku Ohashi). c Vuavua holding her dead infant Veve (photo by Tetsuro Matsuzawa)

(Hamada, unpublished data). Weight increases with age, and the crown-rump length reaches $43 \mathrm{~cm}$, the same size as the hyrax, at 1.5 years of age (Hamada, unpublished data). Vuavua's hyrax-toying involved carrying and grooming the carcass as if it somehow resembled a 1.5-year-old infant chimpanzee. This observation represents the use of an object similar to the real object for play as described in the introduction as one of the developmental stages of pretend play.

\section{An 8-year-old female chimpanzee plays with a log doll}

In the third episode, a young female carried a log doll while following her mother who was carrying her sick infant. The subject was a female chimpanzee named Ja, born in late 1983. The episode happened on January 16, 1992, when Ja was 8 years old. Ja was almost always with her mother Jire, 35 years old, and her younger sister Jokro, aged 2.5 years.
The log-doll episode is part of the story of the death of Jokro (Matsuzawa 2020a).

The infant chimpanzee Jokro caught a respiratory disease, which resulted in her death after a short illness. As the only researcher present at the time, I video-recorded events at the Bureau for 16 days before Jokro's death and 27 days thereafter. The log-doll episode happened when the sick infant was still alive and being carried by her mother. I recorded the log-doll episode, described below, using a still camera and detailed it in a separate report (Matsuzawa 2011).

On January 16, Jokro's condition was worsening. She was sitting on the ground, hardly moving, near her mother. Jokro's older sister Ja walked over to Jokro and invited her to play. When Jokro did not respond to Ja's touch, Ja attempted to get Jokro to play by bending a shrub in her direction. Still, the sick infant did not move. After some nut-cracking, the three chimpanzees ascended to feed on fruits of Antiaris africana trees. Jokro was clinging to her mother.

After eating some fruits, Jire carried Jokro on her back while she moved from one tree to the next. Ja was following 
the mother-infant pair in the canopy when she stopped in a huge Aningeria tree, and broke off a dead branch, ending up with a piece about $50 \mathrm{~cm}$ long and $10 \mathrm{~cm}$ in diameter. Ja then placed this $\log$ on her shoulder and continued following her mother. Ja shifted the log from her shoulder to her armpit to hold it more securely. She then stopped to rest on a big horizontal branch, balancing the log on the branch. She slapped it softly with one hand several times, just like mothers softly slap the back of their infants. Ja then moved off through the trees, carrying the $\log$ for at least $100 \mathrm{~m}$ until she was out of sight. That was the last I saw of her that day: I had no more opportunity to observe the three chimpanzees before evening fell.

Ja seemed to manipulate the $\log$ as if it were a doll (Fig. 3a). The average crown-rump length of a 2.5-year-old female chimpanzee (e.g., Jokro) is $49 \mathrm{~cm}$ (Hamada, unpublished data), similar to the length of the $\log$ that Ja carried and manipulated. The native Manon people in Bossou in fact make dolls out of logs, with braids that mimic hair. Young girls usually hold these logs on their backs and play with them like dolls (Fig. 3b). My impression is that Ja was pretending to take care of her sick sister, using a log doll, just as she had witnessed her mother caring for Jokro. It could also be similar to the actions of young girls in Bossou.

Young chimpanzees at Bossou often carry logs or sticks for various reasons: probing into tree holes, throwing them at humans, hitting other chimpanzees in real or mock aggression, or just playing alone. When they carry logs, branches, vines, or pieces of bark, they often tuck them into their thigh pocket. They also carry them underarm, or with their hands and/or feet and mouth. The log-doll episode presents a variation of playful $\log /$ stick carrying found in the Bossou chimpanzee community.
The use of sticks as play objects has been reported at other field sites as well. Kahlenberg and Wrangham (2010) analyzed 117 cases of "stick carrying" during 14 years of observation of the Kanyawara community in Kibale, Tanzania. They found that the frequency of stick-carrying peaked among juveniles and was higher in females than males. The sex difference may be related to females' greater interest in infant care: they may be carrying sticks like mother chimpanzees carry infants. Actually, in 25 cases in Kanyawara, carried sticks were taken into day-nests. Stick-carrying ceased with motherhood, which means that stick-carrying behavior by juveniles could not have resulted from observing their mothers carrying sticks. Instead, young chimpanzees' carrying of sticks is consistent with practice for adult roles. They may learn socially from other juvenile and adolescent members of the community, similar to the close and careful observation of hyrax-toying by younger females in the Bossou community. The observed sex difference in this kind of pretend play is to be expected, and recalls the greater female proclivity for tool use in the wild (Lonsdorf et al. 2005).

I have witnessed several other cases of log/stick carrying by young chimpanzees in Bossou. However, the log-doll episode involving Ja was unique because the context was clear from the preceding events. It was not real maternal behavior: Ja was following as her mother carried the sick infant, and then she started to play with a log, that was not typical of those used in stick-play at Bossou; it strongly resembled the size and shape of the sick infant, and the log dolls of Manon girls. Thus, Ja's log-doll episode might be the best example so far of pretend play by wild chimpanzees.

\section{a}

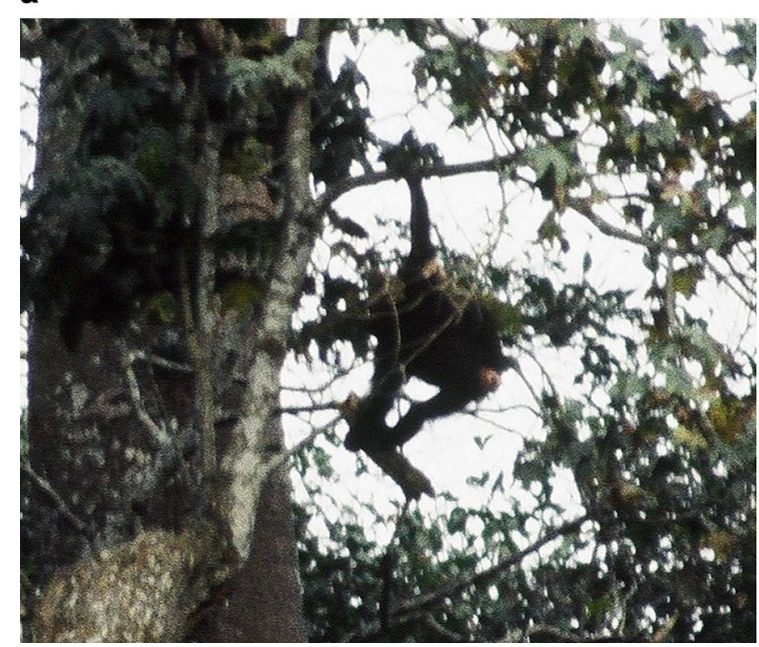

b

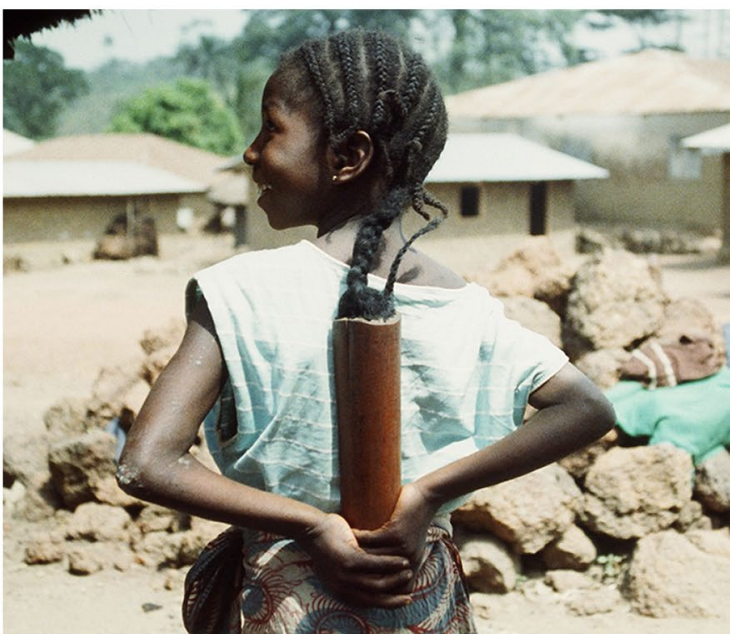

Fig. 3 a Ja carrying the log doll (Photo by Tetsuro Matsuzawa). b A Manon girl carrying a log doll (Photo by Tetsuro Matsuzawa) 


\section{Pretend play in captive chimpanzees}

Imitation and pretense have been hot topics in the study of chimpanzee cognition, resulting in many publications about chimpanzees and other apes that were human-reared (Bard and Leavens 2014; Carrasco et al. 2009; Custance et al. 1995; Jensvold and Fouts 1993: Gómez and MartínAndrade 2002; Gómez 2008; Hayes 1951; Hayes and Hayes 1952; Hopper 2010; Lyn et al. 2006; Mitchell 2002). This article has added to this valuable literature by presenting cases observed in the wild. Now, I will introduce episodes of pretend play in captivity. I have observed chimpanzees in the Primate Research Institute of Kyoto University (PRI) since December 1976. Based on my daily observations of 16 chimpanzees in test rooms and their naturalistic enclosure, I am confident that the episodes seen in the wild have close counterparts in captive settings.

The first captive episode is the counterpart of wearing the grass cushion, the use of a real object for pretend play. On the evening of October 3, 1989, Ai chimpanzee (13-year-old female, GAIN-ID 0434, see the ID system: https://shigen.nig.ac.jp/gain/top.jsp) escaped from her cage and proceeded to play in areas normally reserved for human caretakers and researchers (Matsuzawa 1990). Ai found a key and used it to unlock her own cage, then her partner Akira's (13.5-year-old male, GAIN-ID 0435), and her orangutan friend Doudou's (10-year-old male, GAIN-ID 9016). Two graduate students, Shoji Itakura and Masaki Tomonaga, discovered Ai walking on campus, holding a key between her lips. They called to inform me about the situation. Once liberated, the three apes acted in very different ways. Akira managed to leave the institute and wondered into the neighboring residential area. Doudou stayed close to the open cage door and simply played with various objects nearby. Ai presented her bottom to the two students as a submissive signal and then went to the dining quarter of the institute. First, she went into the kitchen and played with water. She turned on the tap and made bubbles by adding soap powder to the flowing water. The key was found in the sink later. Ai then took a bunch of bananas and went into the staff room, where she was found by a caretaker. She left again via the kitchen and went out to the campus space, where she met me. I said "Ai!" in a strong voice. Ai looked at me and spontaneously presented me with the whole bunch of bananas. It seemed flattering. I accepted the offer and gave one banana back to her, which she ate. Then, she slowly walked into the administration office, picked up a telephone, typed on a keyboard, leafed through some documents, scribbled on them with a ballpoint pen, and pulled other documents off the shelves. She then put the kettle on the stove and tried to turn on the gas, but at this point I mildly intervened to stop her. Ai used to take walks with me on campus, until she was 9 years old. She had seen humans performing the above behaviors for years but never had the opportunity to do so herself until now. These episodes were not video-recorded but many campus personnel and students witnessed them. Ai's behavior can be described as examples of deferred imitation similar to that studied in juvenile chimpanzees and orangutans (Bering et al 2000; Russon and Galdikas 1993). On another occasion in PRI, a caretaker left the chimpanzee Puchi (adult female, GAIN-ID 0436) alone in her cage as he took a break from cleaning the floor. Puchi picked up the hose in her right hand to spray water, and held the brush in the left hand to scrub the floor.

The second episode is the counterpart of hyrax-toying: using an object that is similar to the real thing but not the real thing. This concerns a series of structured tests for object play in chimpanzees, conducted by Tamiko Ogura, Misato Hayashi, and me (Matsuzawa et al. 2003). The entire process was video-recorded. On February 25, 2003, we gave a toy phone to Chloe (22-year-old female, GAIN-ID 0441), accompanied by Cleo, her 2-year-old daughter (GAIN-ID 0609), in a face-to-face situation (Supplementary video 3 and openly accessible video: https://youtu.be/ofJAlBegzcE). Chloe had seen people using phones but had never manipulated one. I picked up the toy phone's handset from the floor and talked into it (Fig. 4a). Then I put it back on the floor. Chloe immediately picked up the handset with her right hand and put it to her right ear (Fig. 4b). Twelve seconds later, she transferred the handset to her left hand and placed it against my right ear (Fig. 4c). So I started talking into the handset again as if I could hear a voice from it. Chloe looked at the receiver end of the handset, kissed it and then put it back to my ear again. Besides this toy phone episode, toying with real animals has also been seen in PRI chimpanzees: Reiko (GAIN-ID 0432) with a dead rat and Pal (GAIN-ID 0611) with a frog. Stick-carrying was also a popular form of play for Cleo. Interestingly, these chimpanzees were all young, juvenile females at the time of the episodes.

The third episode is the counterpart of the log doll: using an object quite different in form than the real target. This was actually a follow-up to the Chloe-phone episode. A few minutes after that episode, we replaced the toy phone with a wooden rod, $2 \mathrm{~cm}$ in diameter and $10 \mathrm{~cm}$ long. It was just a simple rod, but I put it to my ear and started talking, pretending to be using a real phone. After talking, I put the rod back on the floor. Chloe picked it up and put it to my ear. She spontaneously used the rod as a substitute for the real phone. In a similar vein, another impressive instance of pretense was shown by $\mathrm{Ai}$ at the age of 5 . Ai was with three playmates of similar age: Akira, Mari and Pendesa, in the outdoor compound. Junzo Inagaki and I joined them and we played together. After playing with us, Ai turned to solitary play. She used a red cup to scoop up sand on the ground, and then held the cup 
a

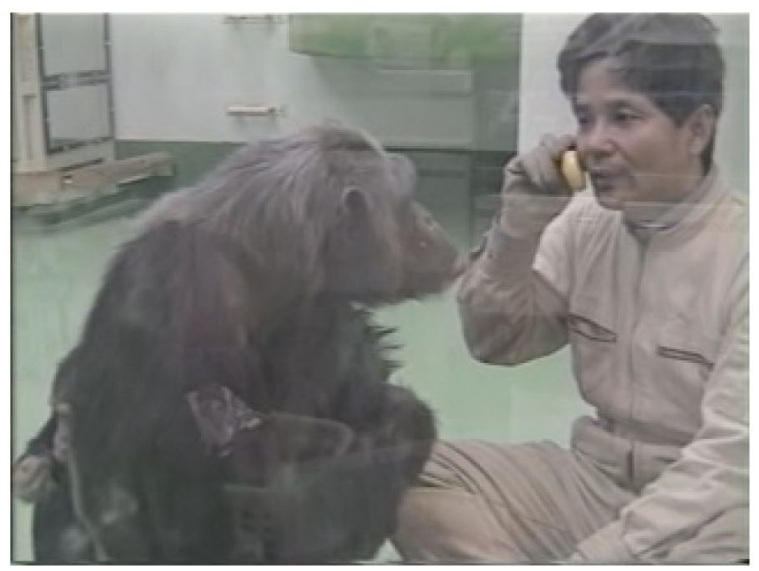

b

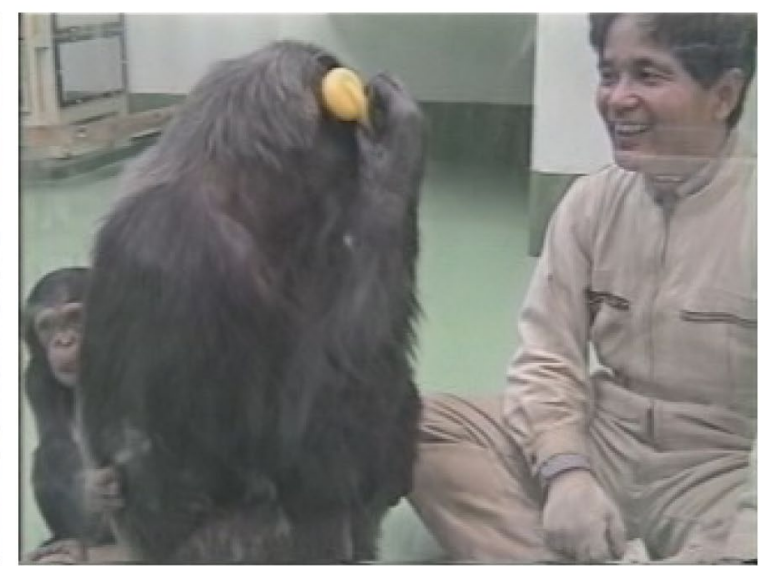

C

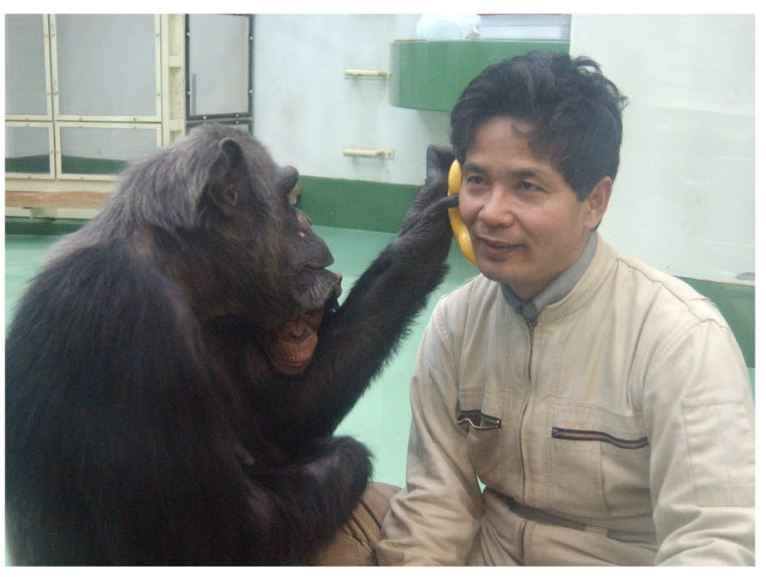

Fig. 4 a Chloe and a toy phone (photo from the video by Tamiko Ogura and Misato Hayashi). b Chloe holding the toy phone against her ear (photo from the video by Tamiko Ogura and Misato Hayashi). c Chloe holding the toy phone against the author's ear (Photo by Akihiro Hirata, Mainichi Newspaper) at eye level and started tilting it to pour out the sand. She extended her lower lip as if to catch the falling sand, but she stopped right before the sand made contact with her mouth. In the compound there was a small fountain. Akira and Mari always drank by taking water directly by the mouth, but Pendesa and Ai sometimes used the red cup to scoop and drink. Ai typically held the cup at eye level and gently tilted it to pour the water into her extended lower lip and mouth: I understood that during the play episode the sand represented water, which she briefly pretended to drink.

Other captive chimpanzees have often been seen to show similar episodes. Hayes and Hayes (1952) assessed a 3-year-old home-raised chimpanzee on a variety of imitation tests, and subsequent studies on language-trained and so-called enculturated chimpanzees also revealed similar sorts of pretending behavior (see e.g., Jensvold and Fouts 1993). In short, the data from chimpanzees in humanrearing settings match the empirical evidence for three categories of pretend play in wild chimpanzees. There are no fundamental differences between wild chimpanzees and captive ones. Pretend play is a natural phenomenon, not an artificial byproduct of living in captivity.

\section{Imaginary play: pretense without objects}

Finally, I would like to describe an extreme version of pretend play in a solitary situation: pretend play without an object. The episode involved no real objects; instead, the chimpanzee performed pretend play with imaginary wooden blocks. The subject was an infant male chimpanzee, Ayumu (born April 24, 2000, GAIN-ID 0608). The episode occurred on January 18, 2003, when Ayumu was 2 years and 8 months old. Given his young age, he was always accompanied by his mother, Ai. The episode was observed by Ari Ueno, Toyomi Matsuno, and me, and pictures of the scene were taken by Akihiro Hirata; it was also 
video-recorded. A summary of the episode was originally reported in Japanese (Matsuzawa et al. 2003).

The observation took place in a testing booth at the PRI where we conducted face-to-face experiments to study cognition in mother-infant chimpanzee pairs (Hayashi and Matsuzawa 2003; Hirata and Celli 2003; Matsuzawa et al. 2006; Myowa et al. 2004; Tomonaga et al. 2004; Tanaka et al. 2003; Ueno and Matsuzawa 2004). My colleagues and I invented a new study paradigm called "participation observation" (Matsuzawa et al. 2006) which is quite different from the traditional way of studying chimpanzees in captivity. The traditional way was the so-called "crossfostering paradigm" (Gardner et al. 1989) that isolated infants from their mothers and forced them to interact with humans in human-rearing settings. In contrast to this, the participation observation paradigm kept mother-reared infant chimpanzees living in a social group in an enriched environment (Matsuzawa 2020b), and the mother-infant pair was invited to join cognitive tests together, based on the triadic relationship among researcher-mother-infant. In this situation, we were able to test the mothers, the infants, or both at the same time. A good example of the latter was a study we conducted on food sharing (Ueno et al. 2004).

During the session on January 18 , I sat across from Ai, testing her ability to copy the arrangement of different colored wooden blocks stacked up in a tower (for example, red-yellow-blue, from the bottom, Hayashi et al. 2009). While Ai was being tested on this task, Ayumu had nothing particular to do. He typically retreated to his favorite position, in a corner of the booth, having collected his own four wooden blocks (red, yellow, blue, and white) before walking backward toward the corner. Holding the blocks in his hands, and with four fingers of each hand touching the floor, as he moved backwards he also slid the blocks across the floor. He moved like this, slowly, until he reached his destination. Once there, he started playing alone with the blocks.

On January 18, Ai and Ayumu arrived at the testing booth at 09:13. During tests conducted on previous days, on January 15 and 17, nothing unusual had happened, and this session started the same way. Ayumu collected his four blocks and moved to the corner with them. There, he briefly lay down on his back, flailing his arms and legs in the air, surrounded by the four blocks. Then, at 09:32, Ayumu suddenly got up, put his hands together and, with fingertips softly touching the floor, slowly started moving backwards (Fig. 5a, b). His posture and movement were exactly the same as when he dragged the real blocks. However, this time there was nothing in his hands: they were empty. His face relaxed into an open-mouth expression, the so-called "play face".

At one point, Ayumu's direction was impeded by the red block. He carefully avoided this block by moving his hands sideways around it: the left hand circled out left and the right hand right, so as not to touch the red block in the middle (Fig. 5c). His fingers maintained contact with the floor. He moved backwards like this until he reached Ai and me, then he turned around and went back to his corner, again stepping slowly backwards as he did with the real blocks.

The scene was filmed using two video camcorders (see supplementary video 4 and openly accessible video at the following site: https://langint.pri.kyoto-u.ac.jp/ai/ja/gallery/ Matsuzawa2020-Primates.html). Ayumu's behavior was so unexpectedly funny that one of the graduate students filming the scene could not stop laughing. Ayumu's play face gradually turned serious, and he rushed toward the student and banged on the acrylic panel in front of her. To us, it looked like Ayumu was protesting: "Don't laugh at me!".

Ayumu's behavior is a clear example of pretend play: the dragging of imaginary blocks. Three observations support this interpretation. First, real block-dragging behavior and the behavior we observed in this episode appear identical, the only difference being the presence or absence of the blocks. In both cases, Ayumu showed the same movements: stepping backwards, fingers gently raking along the floor. Second, Ayumu carefully avoided the red block along the way. His intention was to bring the imaginary blocks to us, and hence there was no more space in his hands for a real block. Third, his relaxed, open-mouth play-face throughout the performance showed his intention to play. This episode of pretend play - the dragging of imaginary blocks-provides further evidence of the power of imagination in young chimpanzees.

We continued face-to-face tests with Ai and Ayumu. The same kind of pretend play happened again 6 months later on July 18, 2004, when Ayumu was 3 years and 2 months old. That day we were testing Ayumu's ability to stack blocks. He spontaneously made towers of 3-4 blocks. Then, at 09:46, Ayumu started showing pretend dragging of imaginary blocks: stepping backwards, again with his fingers gently raking along the floor. He walked round and round the booth in this way, pretending to drag imaginary blocks. Although we continued the face-to-face tests, this was the last time we witnessed imaginary play by Ayumu.

\section{Discussion}

Above, I have summarized evidence for imagination in the form of pretense or pretend play in chimpanzees. In the wild, Flanle put the grass cushion on his head. Vuavua groomed the hyrax in her night nest. Ja carried the log doll as she followed her mother carrying her infant. These three episodes from the wild map nicely onto examples reported in humanreared chimpanzees. Thus, we may conclude that pretense is universal in not only humans but also chimpanzees, wherever 
Fig. 5 a Ayumu dragging the real wooden blocks (Photo by Akihiro Hirata, Mainichi Newspaper). b Ayumu dragging the imaginary blocks (photo from the video by Ari Ueno and Toyomi Matsuno). c Ayumu avoiding the red block during imaginary play (photo from the video by Ari Ueno and Toyomi Matsuno) a

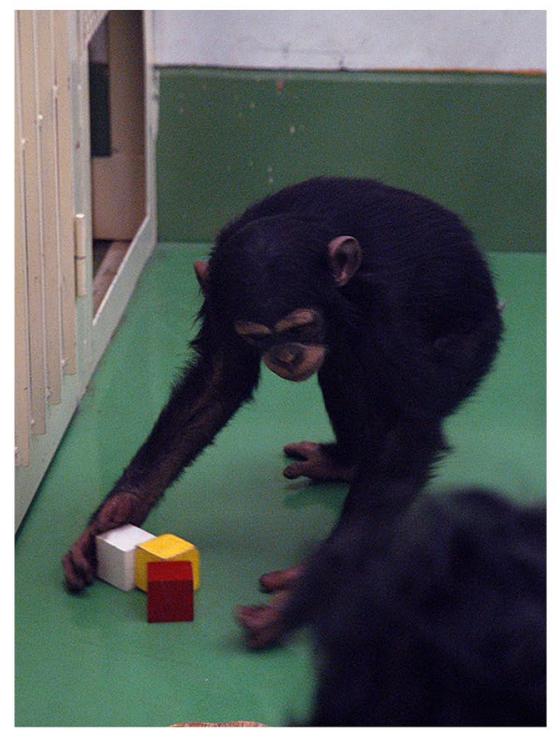

b

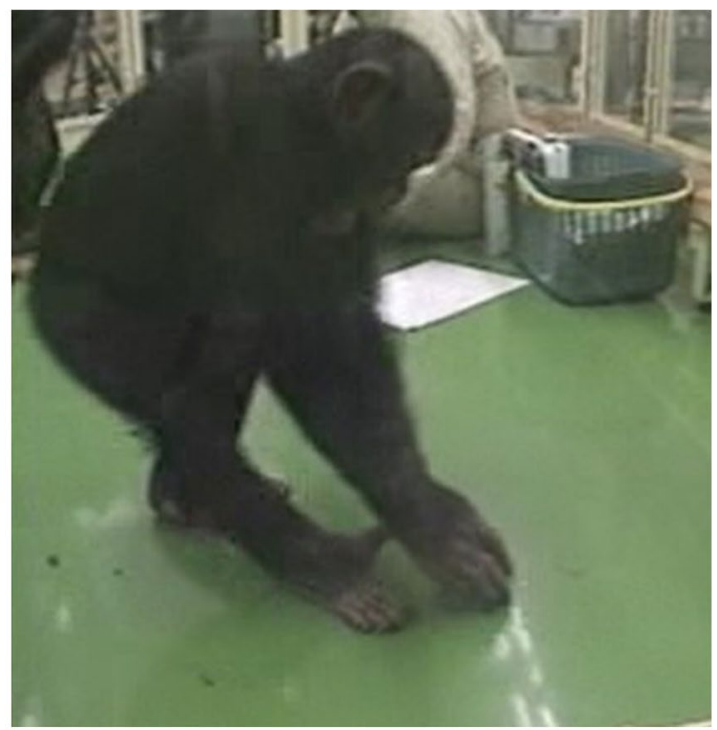

C

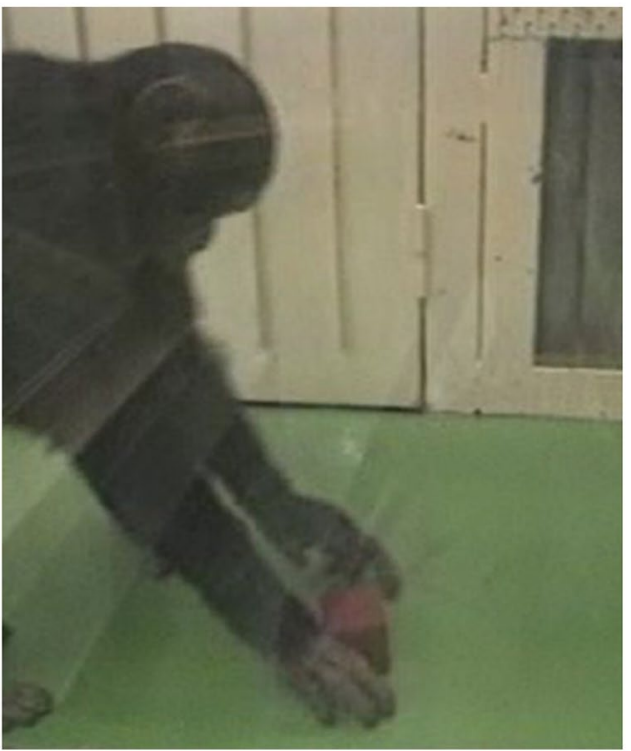

they grow up. Notably, in the laboratory, Ayumu dragged imaginary blocks; no real objects were used at all. Taken together, these observations suggest that pretense might start at the age of 2-3 years in chimpanzees, slightly later than in humans. There may be a series of developmental stages of pretense, from using real or similar objects, to using different objects, and finally pretending without objects.

Pretend play begins early in human life, emerging somewhere between the ages of 1 and 2 years. Pretense in infants extends their imagination into social contexts. Preschoolers, around 3 to 5 years of age, are more capable of imagining different roles in their pretend play. They assign roles to themselves and others, for example pretending to be a doctor in a hospital, or to be selling goods to customers in a shop. Thus, human pretend play develops into more complex forms of role-play. However, in chimpanzees, I saw no evidence of pretense play transforming into any kind of role-play in social settings.

All of the episodes observed in the wild were solitary play: grass cushion, hyrax-toying, and log doll. There was no social involvement by mothers, other adults, or even other youngsters in these episodes. In fact, other individuals paid little attention to what the players were doing, neither encouraging nor getting involved (the exception being when Fanle, the mother, appeared to try to stop her young son's play with a grass head cushion). In short, there was no social feedback from the other members of the community in chimpanzees. This is in clear contrast to humans. Human mother-infant pairs interact through pretend play, which, like imitation, may be intrinsically motivated, requiring no 
extrinsic reward or feedback from others. However, social interaction might have an important role in facilitating and enhancing this ability (Persson et al, 2018).

Chimpanzee social cognition has long been studied in laboratory settings. Among other phenomena, pointing, gaze following, joint attention, intentionality, empathy, helping, perspective-taking, and theory of mind (understanding others' mental states) have been tested in captivity, but they have rarely been explored in the wild. However, there might be ways to approach these socio-cognitive abilities in the apes' natural habitats. One possibility is to introduce a clear cognitive and developmental perspective into field studies through careful observation (Matsuzawa et al. 2006; Matsuzawa 2007). Several pioneering studies have been focusing on the development of behavioral repertoires in communication and social interaction among wild chimpanzees (Bründl et al. 2020; Goodall 1986; Hobaiter and Byrne 2011, 2014; Nishida et al 1999, 2010; Pika and Mitani 2006; Plooij 1984). For example, careful observation has brought us cases of what may be referred to as "social imaginary play": pretend play with imaginary companions. An 8-yearold adolescent male in Mahale, Tanzania, was observed to wrestle with branches while emitting his play pant (Hayaki 1985). An adolescent male of 10 years in Bossou, Guinea, performed a mock fight against his own left leg while also emitting the play pant (Nakamura 2012).

Field experiments such as those done at the Bossou outdoor laboratory can also be valuable in this line of research. Advantages for analyzing social interactions include getting a clear, obstacle-free view, keeping conditions identical over time and observations always at the same place, following developmental changes in the same individuals across years or even decades, and video-records for objective and detailed behavioral coding. Furthermore, although field experiments are done in a natural setting, some critical parameters can be manipulated, such as the availability of objects (e.g., potential tools, puzzles, foods). Additionally, through our observations on lithic technology, we were able to witness more of the richness of the chimpanzees' natural social cognition, in maternal care, allomothering, grandmothering, greetings, sexual invitation and intercourse, grooming, charging and dominance displays, aggression, consolation and reassurance, alliance formation, helping, possible teaching, and so on. For example, we recorded clear cases of tactical deception that may have similar roots to pretense. When we created a competitive situation by reducing the number of stones available for nut cracking, a chimpanzee deceived her son to get him to hand over a coveted hammer stone (Matsuzawa 1999). (see https://www.greencorridor.info/en/ videos/Nut-cracking/15-Deception.html) In another example, a young chimpanzee pretended to play with her older sister to steal her palm nut (see https://www.greencorridor.
info/en/videos/Learning-nut-cracking/24-Stealing_her_sibli ng_s_nut.html).

A major trend in behavioral research on animals is toward large sample sizes, in the laboratory as well as in the field. Large sample sizes facilitate statistical analyses that are believed to be essential for scientific understanding. However, there might be another perspective that leads to valuable insights based on careful observations and detailed descriptions of single and rare cases. This article has tried to showcase the possibility of studying pretense in the wild. Pretense provides a window for understanding the power of imagination. Further studies in the field on related topics may throw light on the evolutionary pathways that have led to modern humans' unique power of imagination. The power of imagination allows us to contemplate the future, look back at the past, and think in new ways about others. Comparative research on these topics appears particularly relevant in view of the multiple crises that we all face at this moment.

Acknowledgements I am grateful to my colleagues who allowed me to share our observations of three episodes in the wild and some others in captivity: Satoshi Hirata, Shiho Fujita, Ari Ueno, Toyomi Matsuno, Gaku Ohashi, Misato Hayashi, Shinya Yamamoto, and Tamiko Ogura. I appreciate the efforts of Satoshi Hirata who edited the video recordings of hyrax-toying. I also thank Yuzuru Hamada who offered unpublished somatometric data on chimpanzees. Thanks are due to Tomoko Takashima, Makiko Uchikoshi, and Akiho Muramatsu, who searched the behavioral records kept in PRI. Local guides and collaborators at Bossou and Nimba also offered invaluable help, in particular Gouano Goumy, Tino Zogbila, Paquilé Chérif, Pascal Goumy, Jules Doré, Boniface Zogbila, Henry Zogbila, Guanou Zogbila, Vincent Traoré, Buna Zogbila, Nyonko Traoré, Remy Traoré, Dogouka Samy, Fokaye Zogbila, Fromo Doré, and Kassié Doré. Long-running fieldwork in Bossou was initiated by Prof. Yukimaru Sugiyama in 1976. The Bossou-Nimba project has been running continuously for 45 years, from 1976 until now. This has been achieved by international collaboration among researchers including Yukimaru Sugiyama, Gen Yamakoshi, Hiroyuki Takemoto, Tatyana Humle, Dora Biro, Gaku Ohashi, Misato Hayashi, Claudia Sousa, Nicolas Granier, Laura Martinez, Kimberly Hockings, Katelijne Koops, Susana Carvalho, Naruki Morimura, and younger generations, with Guinean scholars such as Jeremie Koman, Soh Pletah Bonimy, Bakary Coulibary, Tamba Tagbino, Makan Kourouma, Mamadou Diakite, Cécé Kolié, Iba Conde, Aly Gaspard Soumah, and Sékou Moussa Keita. I also thank Guinean authorities who permit us to do the long-running field study: Ministre de l'Enseignement Supérieur et de la Recherche Scientifique, Direction Générale de la Recherche Scientifique et de l'Innovation Technologique, Centre d'Étude et de Recherche en Environnement, Centre Universitaire de N'Zérékoré, and Institut de Recherche Environnementale de Bossou (IREB). Special thanks to Mon. Abdoulaye Yéro Baldé, Dr. Binko Mamady Toure, Dr. Mafory Bangoura, Prof. Sékou Moussa Keita, Dr. Ousmane Wora Diallo, and Dr. Soumah Aly Gaspard who are leading these organizations. The laboratory work has been done in PRI : Thanks are due to the faculty members, veterinarians, other staffs and graduate students in the Section of Language and Intelligence and Center for Human Evolution Modeling Research that have been taking care of a group of PRI chimpanzees. Financial support for preparing the manuscript came from MEXT-JSPS Grants \#24000001 and \#16H06283; LGPU04-PWS, JSPS Core-to-Core Program CCSN, and GAIN (Great Ape Information Network) to the author. I also thank my colleagues, James 
Anderson, Satoshi Hirata, Masako Myowa-Yamakoshi, Misato Hayashi, and Miho Nakamura, and Maegan Fitsgerald for their valuable advice and comments on the draft. Special thanks to Dr. James Anderson and Dr. Dora Biro for their efforts in reviewing and editing the English text.

\section{References}

Bard KA, Leavens DA (2014) The importance of development for comparative primatology. Annual Rev Anthrop 43:183-200. https:// doi.org/10.1146/annurev-anthro-102313-030223

Bering JM, Bjorklund DF, Ragan P (2000) Deferred imitation of objectrelated actions in human-reared juvenile chimpanzees and orangutans. Dev Psychobiol 36(3):218-232. https://doi.org/10.1002/ (SICI)1098-2302(200004)36:3<218:AID-DEV5>3.0.CO;2-K

Biro D, Inoue-Nakamura N, Tonooka R, Yamakoshi G, Sousa C, Matsuzawa T (2003) Cultural innovation and transmission of tool use in wild chimpanzees: evidence from field experiments. Anim Cogn 6:213-223

Biro D, Humle T, Koops K, Sousa C, Hayashi M, Matsuzawa T (2010) Chimpanzee mothers at Bossou, Guinea, carry the mummified remains of their dead infants. Curr Biol 20(8):R351-R352. https ://doi.org/10.1016/j.cub.2010.02.031

Boesch C, Boesch H (1989) Hunting behavior of wild chimpanzees in the Taï National Park. Amer J Pysical Anthrop 78(4):547-573. https://doi.org/10.1002/ajpa.1330780410

Bründl AC, Tkaczynski PJ, Nohon Kohou G, Boesch C, Wittig R, Crockford C (2020) Systematic mapping of developmental milestones in wild chimpanzees. Develop Science. Wiley, Hoboken. https://doi.org/10.1111/desc.12988

Carrasco L, Posada S, Colell M (2009) New evidence on imitation in an enculturated chimpanzee (Pan troglodytes). J Comp Psychol 123(4):385-390. https://doi.org/10.1037/a0016275

Custance D, Bard K, Whiten A (1995) Can young chimpanzees (Pan troglodytes) imitate arbitrary actions? Hayes and Hayes (1952) revisited. Behaviour 132(11-12):837-859. https://doi. org/10.1163/156853995X00036

Eible-Eibesfeldt I (1989) Human ethology. Aldine de Gruyter, New York

Fein G (1981) Pretend play in childhood: an integrative review. Child Dev 52(4):1095-1118

Gardner A, Gardner BT, Van Cantfort TE (1989) Teaching sign language to chimpanzees. SUNY Press, New York

Gómez JC (2008) The evolution of pretence: from intentional availability to intentional non-existence. Mind Lang 23(5):586-606. https://doi.org/10.1111/j.1468-0017.2008.00353.x

Gómez JC, Martín-Andrade B (2002) Possible precursors of pretend play in non-pretend actions of captive gorillas (Gorilla gorilla). In: Mitchell RW (ed) Pretending and imagination in animals and children. Cambridge Univ Press, Cambridge, pp 255-268

Goodall J (1986) The chimpanzees of Gombe: patterns of behavior. Belknap Press of Harvard University Press, Cambridge

Hayaki H (1985) Social play of juvenile and adolescent chimpanzees in the Mahale Mountains National Park, Tanzania. Primates 26:343360. https://doi.org/10.1007/BF02382452

Hayashi M, Matsuzawa T (2003) Cognitive development in object manipulation by infant chimpanzees. Anim Cogn 6:225-233. https ://doi.org/10.1007/s10071-003-0185-8

Hayashi M, Sekine S, Tanaka M, Takeshita H (2009) Copying a model stack of colored blocks by chimpanzees and humans. Interact Stud 10(2):130-149. https://doi.org/10.1075/is.10.2.03hay

Hayes C (1951) The Ape in our house. Harper and Row, New York

Hayes KJ, Hayes C (1952) Imitation in a home-raised chimpanzee. J Comp Physiol Psychol 45(5):450-459. https://doi.org/10.1037/ h0053609
Heimann M, Meltzoff AN (1996) Deferred imitation in 9- and 14-month-old infants: a longitudinal study of a Swedish sample. Br J Dev Psychol 14(1):55-64. https://doi.org/10.1111/j.2044835X.1996.tb00693.x

Hirata S, Celli M (2003) Role of mothers in the acquisition of tool-use behaviors by captive infant chimpanzees. Anim Cogn 6:235-244. https://doi.org/10.1007/s10071-003-0187-6

Hirata S, Mizumo Y (2011) Animal toying. In: Matsuzawa T, Humle $\mathrm{T}$, Sugiyama Y (eds) The chimpanzees of Bossou and Nimba. Springer, Tokyo, pp 137-141

Hirata S, Yamakoshi G, Fujita S, Ohashi G, Matsuzawa T (2001) Capturing and toying with hyraxes (Dendrohyrax dorsalis) by wild chimpanzees (Pan troglodytes) at Bossou Guinea. Amer J Primatol 53(2):93-97. https://doi.org/10.1002/1098-2345(20010 2) 53:2<93:AID-AJP5>3.0.CO;2-X

Hobaiter C, Byrn RW (2011) The gestural repertoire of the wild chimpanzee. Anim Cogn 14:745-767. https://doi.org/10.1007/s1007 1-011-0409-2

Hobaiter C, Byrne RW (2014) The meanings of chimpanzee gestures. Current Biol 24(14):1596-1600. https://doi.org/10.1016/j. cub.2014.05.066

Hockings K, Humle T, Carvalho S, Matsuzawa T (2012) Chimpanzee interactions with nonhuman species in an anthropogenic habitat. Behaviour 149:299-324. https://doi.org/10.1163/156853912X 636735

Hopper LM (2010) Deferred imitation in children and apes. Psychologist 23(4):294-297

Hosaka K, Nakamura M, Takahata Y (1980s) Longitudinal changes in the targets of chimpanzee (Pan troglodytes) hunts at Mahale Mountains National Park: how and why did they begin to intensively hunt red colobus (Piliocolobus rufomitratus) in the 1980s? Primates 61:391-401. https://doi.org/10.1007/s10329-020-00803 $-8$

Humle T (2011) The 2003 epidemic of a flu-like respiratory disease at Bossou. In: Matsuzawa T, Humle T, Sugiyama Y (eds) The chimpanzees of Bossou and Nimba. Springer, Tokyo, pp 323-325

Ihobe H (1990) Interspecific interactions between wild pygmy chimpanzees (Pan paniscus) and red colobus (Colobus badius). Primates 31:109-112. https://doi.org/10.1007/BF02381033

Inoue S, Matsuzawa T (2007) Working memory of numerals in chimpanzees. Curr Biol 17(23):R1004-R1005. https://doi. org/10.1016/j.cub.2007.10.027

Inoue-Nakamura N, Matsuzawa T (1997) Development of stone tool use by wild chimpanzees (Pan troglodytes). J Comp Psychol 111:159-173. https://doi.org/10.1037/0735-7036.111.2.159

Jensvold MLA, Fouts RS (1993) Imaginary play in chimpanzees (Pan troglodytes). Hum Evol 8:217-227

Kahlenberg SM, Wrangham RW (2010) Sex differences in chimpanzees' use of sticks as play objects resemble those of children. Curr Biol 20(24):R1-67-R1068. https://doi.org/10.1016/j. cub.2010.11.024

Lillard AS (1993) Pretend play skills and the child's theory of mind. Child Dev 64(2):348-371. https://doi. org/10.1111/j.1467-8624.1993.tb02914.x

Lillard AS, Lerner MD, Hopkins EJ, Dore RA, Smith ED, Palmquist CM (2013) The impact of pretend play on children's development: a review of the evidence. Psychol Bull 139(1):1-34. https://doi. org/10.1037/a0029321

Lockman JJ (2000) A perception-action perspective on tool use development. Child Dev 71(1):137-144. https://doi. org/10.1111/1467-8624.00127

Lonsdorf EV (2005) Sex differences in the development of termite-fishing skills in the wild chimpanzees, Pan troglodytes schweinfurthii, of Gombe National Park Tanzania. Anim Behav 70(3):673-683. https://doi.org/10.1016/j.anbehav.2004.12.014 
Lyn H, Greenfield P, Savage-Rumbaugh S (2006) The development of representational play in chimpanzees and bonobos: evolutionary implications, pretense, and the role of interspecies communication. Cognit Dev 21(3):199-213. https://doi.org/10.1016/j.cogde v.2006.03.005

Matsuzawa T (1990) Chimpanzees run away. Hattatsu 41:62-72 (in Japanese)

Matsuzawa T (1994) Field experiments on use of stone tools by chimpanzees in the wild. In: Wrangham RW, McGrew WC, de Waal FBM, Heltne PG (eds) Chimpanzee cultures. Harvard University Press, Cambridge, pp 351-370

Matsuzawa T (1999) Communication and tool use in chimpanzees: cultural and social contexts. In: Hauser MD, Konishi M (eds) The design of animal communication. MIT Press, Cambridge, pp 645-671

Matsuzawa T (2007) Comparative cognitive development. Dev Sci 10(1):97-103. https://doi.org/10.1111/j.1467-7687.2007.00570.x

Matsuzawa T (2009) Symbolic representation of number in chimpanzees. Curr Opin Neurobiol 19(1):92-98. https://doi.org/10.1016/j. conb.2009.04.007

Matsuzawa T (2011) Log doll: pretense in wild chimpanzees. In: Matsuzawa T, Humle T, Sugiyama Y (eds) The chimpanzees in Bossou and Nimba. Springer, Tokyo, pp 131-135

Matsuzawa T (2020a) Jokro: the death of a wild infant chimpanzee from respiratory disease. Primates 61:339-346. https://doi. org/10.1007/s10329-020-00819-0

Matsuzawa T (2020b) WISH cages: constructing multiple habitats for captive chimpanzees. Primates 61:139-148. https://doi. org/10.1007/s10329-020-00806-5

Matsuzawa T, Yamamoto S (2011) Little chimpanzees (111): advantages of field experiment. Kagaku 81:212-283 (in Japanese)

Matsuzawa T, Ueno A, Matsuno T, Hayashi M (2003) Little chimpanzees (16): imitation and pretense. Kagaku 78:482-483 (in Japanese)

Matsuzawa T, Tanaka M, Tomonaga M (eds) (2006) Cognitive development in chimpanzees. Springer, Tokyo

Matsuzawa T, Humle T, Sugiyama Y (eds) (2011) The chimpanzees of Bossou and Nimba. Springer, Tokyo, p 465

McGrew W (1992) Chimpanzee material culture. Cambridge Univ Press, Cambridge

Mitchell R (ed) (2002) Pretending and imagination in animals and children. Cambridge Univ Press, Cambridge. https://doi.org/10.1017/ CBO9780511542282

Myowa-Yamakoshi M, Matsuzawa T (1999) Factors influencing imitation of manipulatory actions in chimpanzees (Pan troglodytes). $\mathrm{J}$ Comp Psychol 113(2):128-136

Myowa-Yamakoshi M, Matsuzawa T (2000) Imitation of intentional manipulatory actions in chimpanzees (Pan troglodytes). J Comp Psychol 114(4):381-391. https://doi. org/10.1037/0735-7036.114.4.381

Myowa-Yamakoshi M, Tomonaga M, Tanaka M, Mastzuawa T (2004) Imitation in neonatal chimpanzees (Pan troglodytes ). Dev Sci 7(4):437-442. https://doi.org/10.1111/j.1467-7687.2004.00364.x

Nakamura M (2012) Playing with his leg: a case of imaginary social play by an adolescent male chimpanzee at Bossou? Pan Afr News 19(1):1-3

Nishida T, Kano T, Goodall J, McGrew WC, Nakamura M (1999) Ethogram and ethnography of Mahale chimpanzees. Anthropl Sci 107:141-188. https://doi.org/10.1537/ase.107.141

Nishida T, Zanma K, Matsusaka T, Inaba A, McGrew WC (2010) Chimpanzee behavior in the wild: an audio-visual encyclopedia. Springer, Tokyo
Ohashi G, Matsuzawa T (2011) Deactivation of snares by wild chimpanzees. Primates 52:1-5. https://doi.org/10.1007/s 1032 9-010-0212-8

Persson T, Sauciuc GA, Madsen EA (2018) Spontaneous cross-species imitation in interactions between chimpanzees and zoo visitors. Primates 59:19-29. https://doi.org/10.1007/s10329-017-0624-9

Piaget J (1962) Play, dreams and imitation in childhood. Norton, New York

Pika S, Mitani J (2006) Referential gestural communication in wild chimpanzees (Pan troglodytes). Curr Biol 16(6):R191-R192

Plooij FX (1984) The behavioral development of free-living chimpanzee babies and infants. Ablex, Norwood

Russon A, Galdikas B (1993) Imitation in free-ranging rehabilitant orangutans (Pongo pygmaeus). J Comp Psychol 107(2):147-161. https://doi.org/10.1037/0735-7036.107.2.147

Sabater Pi J, Bermejo M, Illera G, Vea JJ (1993) Behavior of bonobos (Pan paniscus) following their capture of monkeys in Zaire. Int $\mathrm{J}$ Primatol 14:797-804

Saito A, Hayashi M, Takeshita H, Matsuzawa T (2014) The origin of representational drawing: a comparison of human children and chimpanzees. Child Dev 85(6):2232-2246. https://doi. org/10.1111/cdev.12319

Sanz C, Call J, Boesch C (2013) Tool use in animals: cognition and ecology. Cambridge Univ Press, New York

Schofield D, Nagrani A, Zisserman A, Hayashi M, Matsuzawa T, Biro D, Carvalho S (2019) Chimpanzee face recognition from videos in the wild using deep learning. Sci Adv 5:eaaw0736. https://doi. org/10.1126/sciadv.aaw0736

Sugiyama Y, Koman J (1979) Social structure and dynamics of wild chimpanzees at Bossou, Guinea. Primates 20:323-339

Tanaka M, Tomonaga M, Matsuzawa T (2003) Finger drawing by infant chimpanzees (Pan troglodytes). Anim Cogn 6:245-251. https://doi.org/10.1007/s10071-003-0198-3

Tomonaga M, Tanaka M, Matsuzawa T, Myowa-Yamakoshi M, Okamoto S (2004) Development of social cognition in infant chimpanzees (Pan troglodytes): face recognition, smiling, gaze, and the lack of triadic interactions. Jap Psychol Res 46(3):227-235. https ://doi.org/10.1111/j.1468-5584.2004.00254.X

Udono T, Teramoto M, Hayasaka I (1999)A review of 100 pregnancies in chimpanzees at the Sanwa Kagaku Kenkyusho.Primate Research 15(2): 243-250. https://doi.org/10.2354/psj.15.243 (in Japanese)

Ueno A, Matsuzawa T (2004) Food transfer between chimpanzee mothers and their infants. Primates 45:231-239. https://doi. org/10.1007/s10329-004-0085-9

Whiten A, Goodall J, McGrew W, Nishida T, Reynolds V, Sugiyama Y, Tutin CEG, Wrangham RW, Boesch C (1999) Cultures in chimpanzees. Nature 399:682-685

Yamakoshi G (2001) Ecology of tool use in wild chimpanzees: toward reconstruction of early hominid evolution. In: Matsuzawa T (ed) Primate origins of human cognition and behavior. Springer, Tokyo, pp 537-556

Publisher's Note Springer Nature remains neutral with regard to jurisdictional claims in published maps and institutional affiliations. 